\title{
Meta
}

Journal des traducteurs

Translators' Journal

\section{ZWARTJES, Otto, ZIMMERMANN, Klaus y SCHRADER-KNIFFKI, Martina, eds. (2014): Missionary Linguistics V/Lingüística misionera $V$. Translation theories and practices. Amsterdam y Philadelphia: John Benjamins, 350 p.}

\section{Joaquín García-Medall}

Volume 60, numéro 3, décembre 2015

URI : https://id.erudit.org/iderudit/1036151ar

DOI : https://doi.org/10.7202/1036151ar

Aller au sommaire du numéro

Éditeur(s)

Les Presses de l’Université de Montréal

ISSN

0026-0452 (imprimé)

1492-1421 (numérique)

Découvrir la revue

Citer ce compte rendu

García-Medall, J. (2015). Compte rendu de [ZWARTJEs, Otto, ZimmermanN, Klaus y SCHRADER-KNIFFKI, Martina, eds. (2014): Missionary Linguistics

V/Lingüística misionera $V$. Translation theories and practices. Amsterdam y

Philadelphia: John Benjamins, 350 p.] Meta, 60(3), 648-650.

https://doi.org/10.7202/1036151ar d'utilisation que vous pouvez consulter en ligne. 
parfois une prise de position. Ainsi, un expert peut se voir demander de confirmer la nationalité de la personne interrogée, en se fiant à son accent.

Zwartjes, Otto, Zimmermann, Klaus y Schrader-KNIfFKi, Martina, eds. (2014): Missionary Linguistics V/Lingüística misionera $V$. Translation theories and practices. Amsterdam y Philadelphia: John Benjamins, 350 p.

Las investigaciones sobre la historiografía lingüística misionera conocen un auge extraordinario a lo largo de los últimos años. Los responsables de la edición de este libro tienen mucho que ver en tal explosión de estudios, en especial Otto Zwartjes y Klaus Zimmermann. Estos expertos lingüistas juntos con Martina Scharader-Kniffki han conseguido reunir aquí trabajos que vinculan la investigación de la lingüística misionera con las teorías traductoras y sus prácticas concretas, en concreto las contribuciones de doce expertos en esta área del conocimiento historiográfico.

En el trabajo de Zwartjes (p. 1-50) se demuestra que los misioneros tuvieron en san Jerónimo la fuente teórica más fiable para el desarrollo de sus prácticas traductoras, tanto en lo relativo a la traducción literal (palabra a palabra) como la más libre (traducción del sentido). En muchos géneros pastorales de los misioneros se daba una traducción anotada o glosada que se empleaba como instrumento pedagógico. Los trabajos misioneros revelan una teoría de la traducción y transmiten datos importantes sobre sus prácticas. Los textos son producto de autores europeos que tratan de introducir sus propios discursos en culturas foráneas mediante dos expedientes básicos, la introducción de préstamos desde el español (o el portugués) a las lenguas autóctonas o el uso de los circunloquios o paráfrasis. Los misioneros nunca consideraban las lenguas objeto de su estudio y traducción como lenguas bárbaras sino como idiomas elegantes y refinados. El estudio de Zwartjes es de gran ayuda para una comprensión global de la praxis traductora entre los lingüistas misioneros y, con certeza, sus conclusiones pueden aplicarse a la mayor parte del trabajo misionero hispánico en América y Asia.

La profesora Ríos Castaño (p. 53-83) estudia con detenimiento el Libro de la Rethorica de fray Bernardino de Sahagún (1499-1590), compilado antes de 1547. La autora lleva a cabo un exhaustivo estudio del proceder translaticio, etnográfico y lingüístico para llegar a la conclusión de que dicho trabajo en náhuatl trataba de ser una fuente de referencia para el aprendizaje de la lengua mesoamericana y para el cumplimiento de las obligaciones de proselitismo. Con su labor, Sahagún contribuye a convertir una lengua vernácula de carácter oral en una lengua con tradición literaria y retórica vinculada a los contemporáneos Barbosa y Nuñez de Toledo, así como a Valdés, el Marqués de Santillana, a Horozco y a fray Luis Escobar. Partiendo de la antigüedad retórica europea e hispánica se inserta la lengua y la cultura nahuas en la tradición europea clásica, medieval y renacentista. Sahagún clasifica y ordena la retórica nahua en cuatro subespecies: maneras de hablar, proverbios, adivinanzas y metáforas. No solo aporta los significados literales de expresiones muy ligadas a la cultura nahua, sino que puede incluso proporcionar una ejemplificación correlativa para los lectores hispánicos. Sahagún interpreta y resitúa la cultura nahua originaria de acuerdo con sus parámetros eurocéntricos. Desde luego, lo hace bajo el presupuesto de que los nahuas son seres humanos racionales con altura moral e intelectual capaces de construir, como los europeos, formas altamente articuladas con valor expresivo y retórico.

El profesor Zimmermann (p. 85-112) también analiza la producción etnolingüística de Bernardino de Sahagún y demuestra que el autor interviene en el proceso de creación de los textos nahuas que luego se traducen. Sahagún presenta documentos en dos lenguas en el mismo volumen como modelo para los sermones de futuros misioneros, para lo cual es esencial el confrontamiento textual bilingüe. Por consiguiente, la traducción es un instrumento para dar a conocer el discurso en náhuatl no solo en cuanto a su contenido sino, y no lo menos importante, en cuanto a su forma lingüística. Dichas traducciones son fuentes didácticas para la formación y preparación de los misioneros e implican un rechazo ideológico de su contenido, como corresponde a todo contexto misionero incluso en tiempos modernos. A Sahagún se le presenta el dilema entre la autenticidad del texto traducido y la comprensión por parte de sus posibles lectores (siempre misioneros). Para lograrlo, emplea el trabajo de campo con informantes y se rodea de colaboradores, traductores y correctores. Según Zimmermann, el proselitismo no debe considerarse una mediación, sino más bien una imposición de la verdad de la propia religión y un rechazo de la falsedad de las otras visiones religiosas del mundo. A pesar de ello, Sahagún fue un generador de conocimiento cultural desde el momento en que seleccionó conocimiento a fin de preservarlo y consultarlo en el registro escriturario. Con todo, sus objetivos (como el de toda lingüística misionera) van más allá de la traducción de textos y de lo que hoy se suele considerar la profesión de traductor.

El trabajo de Cristina Monzón (p. 131-159) estudia en profundidad el modelo lexicográfico de Juan Baptista de Lagunas en su Dictionarito en lengua de Michuacan (1574) para el tarasco o 
purépecha. Tras exhaustivo estudio, concluye la autora que empleó Lagunas un modelo alternativo al que inauguró Molina para el náhuatl a partir de Nebrija, según parece suceder también en algunas obras filipinas del siglo XVIII, como el Calepino ilocano de Vivar (1697). Se trata de una obra que no presenta listas de palabras ya configuradas, sino artículos descriptivo-analíticos (en términos de Zimmermann) cuya entrada pueden ser morfemas gramaticales o léxicos: el propósito de Lagunas era "buscar, poner y declarar estas preposiciones, rayces, o primeras posiciones de verbos con sus verdaderos y naturales romances". El resultado es una red de morfemas en una lengua aglutinante ligadas a toda una suerte de posibilidades construccionales que, en opinión de la autora, permitieron al fraile encontrar en las diferencias semánticas y gramaticales aquello que comparten los seres humanos.

Martina Scharader-Kniffki y Yanna Yannakakis (p. 161-199) investigan las prácticas traductoras de la bibliografía misionera hispánica y de los registros judiciales municipales a fin de evaluar la trayectoria aculturadora en la comunidad zapoteca en Nueva España durante el periodo comprendido entre 1574 y 1695 . La tesis a la que llegan las autoras tras el análisis detallad es que la traducción practicada por el pueblo zapoteca, los mestizos y los españoles en contextos evangélicos y jurídico-administrativos producen transformaciones semánticas, de modo que la traducción crea vínculos a través de las fronteras étnicas y lingüísticas. En la práctica, los resultados de la praxis traductora podían ser más ambiguos que fidedignos. Las estrategias traductoras se basaban en los siguientes procederes: a) hacer explícito en la lengua meta (zapoteco) lo que era implícito en la lengua de origen (español); b) parafrasear y repetir, o repetir con negación para reforzar el sentido; c) verbalizar las formas nominales; o bien, d) traducir las categorías abstractas o culturalmente específicas (las Realia, diríamos en teoría de la traducción), a través de la concreción y de la acción. De este modo, cuando los oficiales zapotecas de cabildo elaboraban sus memorias estaban traduciendo a través de contextos culturales diferentes al tiempo que se ubicaban como funcionarios de la Corona y sujetos coloniales. Concluyen los autores que los esfuerzos dominicos para extirpar la idolatría durante la segunda mitad del siglo XVII acabó con una rebelión en la región de los Cajonos en 1700 y las memorias de los escribanos constituían, en dicho contexto histórico, verdaderos instrumentos de negociación política.

El estudio de Cristina Muru (p. 203-230) resulta de especial interés porque se encarga de analizar las traducciones misioneras jesuíticas del tamil (sur de la India) a lo largo de tres periodos diversos, por las obras de Balthasar da Costa (c. 1610-1673), Ippolito Desideri (1684-1733) y Paulo francisco de Noronha (1780-1848). Los misioneros preferían contextualizar el uso de las palabras tamiles según sus propios significados, en lugar de tomarlos prestados de su propia lengua (el portugués o el italiano). De este modo se pretendía la imposición de los conceptos cristianos sobre las ideas hindúes. A menudo se da una adaptación. Sin embargo, los misioneros intentaban transferir un nuevo significado en algunas voces tamiles sin estar seguros nunca de la posible interpretación por parte de los hindúes. Sin duda, esta situación de incertidumbre comunicativa era y es extensible a cualquier tipo de contacto interlingüístico e intercultural. Seguían los jesuitas una política lingüística específica a la hora de adaptar los significados de los signos hindúes relevantes (la idea de Dios, el infierno, el Padre, el bautismo, el paraíso, entre otros, son analizados de acuerdo con los términos tamiles aplicados por los jesuitas). Los misioneros reflexionan sobre las estructuras semánticas de la traducción desde el punto de vista misionero y llevan a cabo una interpretación etnolingüística. De hecho, llegan a distinguir con claridad entre dos registros, el formal y el coloquial, plenamente vigente entre los tamiles de los siglos XVII, XVIII y XIX.

Mariarosaria Gianninoto (p. 231-250) explica cómo la traducción se adoptó entre los siglos XVIII y XIX como parte del proceso de aprendizaje de la lengua china mediante fragmentos por traducir, textos bilingües y recomendaciones sobre cómo traducir al chino y desde el chino a diversas lenguas europeas (latín, inglés, alemán, francés y portugués). Dicha aplicación, acorde con el método gramática-traducción, implicó la adaptación del metalenguaje gramatical occidental para la descripción de la lengua china. Al tiempo, los descriptores occidentales presentaron a occidente algunos conceptos básicos de la tradición metalingüística china. Es el único estudio en donde la intervención misionera se entrevera con la profesional de la pedagogía laica.

El trabajo del profesor Kishimoto (p. 251-272) investiga en profundidad el tratamiento léxico de ciertos términos anatómicos del japonés a lo largo de cinco obras magníficas de la lingüística misionera elaboradas o publicadas desde 1595 a 1696 . Se trata de una investigación en donde se manifiesta con claridad que las posibilidades de investigación en el ámbito de la historiografía misionera son enormes y que apenas hemos empezado a explorarlas. Concluye el autor que algunas diferencias se deben a la disparidad interpretativa que se da entre diferentes autores para términos como $f i$ (bazo), jin (riñones) o can (hígado), entre otros. Los autores del Vocabulario da Lingoa de Iapam... 
(1603-1604) tenían, según el profesor Kishimoto, un conocimiento más profundo de la lengua y la cultura japonesas que los autores del Dictionarium Latino Lusitanicum, ac Japonicum... (1595).

El trabajo de la profesora Rebeca Fernández Rodríguez (p. 273-294) es una investigación sobre la política léxica de los misioneros en diversas lenguas filipinas en lo relativo a términos muy sensibles del discurso católico. Los misioneros dudaban a menudo entre introducir un préstamo hispánico o buscar un equivalente en lengua filipina (tagalo, bisaya, pampango, bicol o ilocano), lo cual derivó en la existencia frecuente de dobletes. En general, optaron por la sustitución e hicieron uso de la extensión semántica para favorecer la conversión. Además, a medida que avanzaba el proceso de colonización se introducían en las lenguas filipinas conceptos y términos cada vez más complejos del discurso católico ('arcángel', 'sacrilegio', 'cónclave', etc.), al tiempo que se iban usando menos hispanismos para designar conceptos religiosos cristianos básicos.

Todos los trabajos analizados son, según creemos, totalmente originales. Sin embargo, el estudio de Sueiro Justel (p. 295-335), con algunas modificaciones, ya fue publicado en fecha tan temprana como 2002 en la revista Traducción \& Comunicación, vol. 3, p. 125-162, por los editores Elena Sánchez Trigo y Óscar Díaz Fouces, con el título "Fray Andrés López, un teórico de la traducción del siglo XVII en la lingüística española en Filipinas". A dicha publicación remitimos al lector.

El volumen es, sin duda, un paso más, y muy relevante, en el conocimiento de la praxis traductora de los lingüistas misioneros católicos en América y Asia desde el siglo XVI hasta el siglo XIX. Nuestras felicitaciones más sinceras a sus editores.

JoAquín García-MEDALL Universidad de Valladolid, Valladolid, España

Pagnoulle, Christine (2012): Traduire les droits. Liège: L3 - Liège Language and Literature, $179 \mathrm{p}$.

Titulaire d'un doctorat en philologie germanique et littérature anglaise, Christine Pagnoulle enseigne à l'Université de Liège. D'emblée, elle mentionne dans son introduction que les régions du monde sont régies par des systèmes juridiques différents et que des traductions, truchement entre les langues et entre les références distinctes, sont donc nécessaires. Cet ouvrage met donc «[...] en évidence les écarts et parfois les incompréhensions qui résultent de cette diversité dans le domaine juridique» (p. 5). Les textes de ce collectif ont été rédigés, pour la plupart, par des enseignants dont les domaines d'expertise sont variés, comme en fait foi leur notice biographique respective. Toutefois, ces personnes s'intéressent toutes à la traduction juridique sous un angle ou un autre. Précisons que Pagnoulle est active dans plusieurs champs de recherche, dont la traduction, la langue et la littérature d'expression anglaise, l'histoire de la littérature et la littérature comparée.

L'ouvrage se décompose en thèmes distincts: les termes, les notions, les doublets, le droit romain et la Common Law ainsi que la question du multilinguisme. Ces thèmes sont envisagés selon une méthode contrastive qui invoque une variété de langues: le français, l'anglais, l'allemand, l'espagnol, l'arabe et le chinois.

Le premier texte, de Françoise Lauwaert, traite des contacts entre droit occidental et droit chinois sous la dynastie des Qing. Suivent certaines des difficultés connexes. Premièrement, la présentation typographique de la traduction des codes qui se caractérise par une assez grande variété de tailles et de styles de caractères ainsi qu'une mise en page particulière, notamment des tableaux:

L'effet visuel produit par le caractère extrêmement concis de la langue chinoise [...] et l'aspect compact des sinogrammes peut être difficilement restitué dans une langue alphabétique et, bien souvent, la dimension synoptique de ces tableaux [...] se perd en traduction. (p. 15)

Deuxièmement, la traduction de la jurisprudence qui, selon l'auteure, est «[...] le produit d'un double processus de "traduction" interne: de la langue orale à la langue écrite d'une part, de la langue ordinaire à la langue bureaucratique, de l'autre [...]» (p. 16). Troisièmement, le droit impérial est essentiellement pénal, ce qui n'est pas le cas du droit occidental. Par conséquent, il n'est pas toujours évident, pour le traducteur, de saisir les nuances entre des termes comme homicide par erreur, homicide par imprudence et homicide par accident. Sans oublier que ces crimes sont punis différemment! Quatrièmement, le manque de mots pour rendre justice à la diversité. La restitution du sens de notions abstraites en droit chinois est particulièrement difficile, une difficulté tenant entre autres «[...] aux sens différents donnés à la notion de justice en Occident et en Chine» (p. 23). Et cinquièmement, l'équivalence aux notions abstraites très présentes dans notre tradition, la langue chinoise étant très analytique et, par certains aspects, bien plus précise que le français (p. 25) Cette observation vaut notamment pour les termes de parenté. En Chine, la «[...] terminologie de la parenté établit en effet une distinction très nette entre l'ensemble des personnes apparentées, d'une 